\title{
The influence of pelvic tilt on stress distribution in the acetabulum: finite element analysis
}

\author{
Kazuhiro Hasegawa ${ }^{1}$, Tamon Kabata ${ }^{2 *}$, Yoshitomo Kajino ${ }^{2}$, Daisuke Inoue ${ }^{2}$, Jiro Sakamoto ${ }^{3}$ and \\ Hiroyuki Tsuchiya ${ }^{2}$
}

\begin{abstract}
Background: Finite element analysis (FEA) has been previously applied for the biomechanical analysis of acetabular dysplasia and osteotomy. However, until now, there have been little reports on the use of FEA to evaluate the effects of pelvic tilt on stress distribution in the acetabulum.

Methods: We used the Mechanical Finder Ver. 7.0 (RCCM, Inc., Japan) to construct finite element models based on 3D-CT data of patients, and designed dysplasia, borderline, and normal pelvic models. For analysis, body weight was placed on the sacrum and the load of the flexor muscles of the hip joint was placed on the ilium. The pelvic tilt was based on the anterior pelvic plane, and the pelvic tilt angles were $-20^{\circ}, 0^{\circ}$, and $20^{\circ}$. The load of the flexor muscle of the hip joint was calculated using the moment arm equation.

Results: All three models showed the highest values of von Mises stress in the $-20^{\circ}$ pelvic tilt angle, and the lowest in the $20^{\circ}$ angle. Stress distribution concentrated in the load-bearing area. The maximum values of von Mises stress in the borderline at pelvic tilt angles of $-20^{\circ}$ was $3.5 \mathrm{Mpa}$, and in the dysplasia at pelvic tilt angles of $0^{\circ}$ was $3.1 \mathrm{Mpa}$.

Conclusions: The pelvic tilt angle of $-20^{\circ}$ of the borderline model showed equal maximum values of von Mises stress than the dysplasia model of pelvic tilt angle of $0^{\circ}$, indicating that pelvic retroversion of $-20^{\circ}$ in borderline is a risk factor for osteoarthritis of the hip joints, similar to dysplasia.
\end{abstract}

Keywords: Finite element analysis, Osteoarthritis, Pelvic tilt, Acetabular dysplasia

\section{Background}

Osteoarthritis of the hip is the primary disease resulting in total hip arthroplasty (THA). In Japan, acetabular dysplasia is one of the most important factors associated with osteoarthritis of the hip $[1,2]$. Acetabular dysplasia results in decreased acetabular cover of the femoral head and increased pressure on the hip, which generates articular cartilage failure, causing osteoarthritis of

\footnotetext{
*Correspondence: tamonkabata@yahoo.co.jp

${ }^{2}$ Department of Orthopaedic Surgery, Graduate School of Medical

Science, Kanazawa University, 13-1 Takaramachi, Ishikawa

920-8641 Kanazawa, Japan

Full list of author information is available at the end of the article
}

the hip. Generally, acetabular dysplasia is evaluated using the central-edge (CE) angle on radiographs (anteroposterior view) $[3,4]$. However, osteoarthritis of the hip joint occasionally develops in patients with a normal CE angle. Moreover, pelvic retroversion has been recently shown to result in decreased acetabular cover of the femoral head, causing osteoarthritis of the hip [5].

Finite element analysis (FEA) has been used in the biomechanical analysis of osteotomy, arthroplasty, joint and the spine area. However, few reports exist using FEA to evaluate the effects of pelvic tilt on stress distribution in the acetabulum [6-12]. Therefore, in the present study, we evaluated the effects of pelvic tilt on stress original author(s) and the source, provide a link to the Creative Commons licence, and indicate if changes were made. The images or other third party material in this article are included in the article's Creative Commons licence, unless indicated otherwise in a credit line to the material. If material is not included in the article's Creative Commons licence and your intended use is not permitted by statutory regulation or exceeds the permitted use, you will need to obtain permission directly from the copyright holder. To view a copy of this licence, visit http://creativecommons.org/licenses/by/4.0/. The Creative Commons Public Domain Dedication waiver (http://creativeco mmons.org/publicdomain/zero/1.0/) applies to the data made available in this article, unless otherwise stated in a credit line to the data. 
distribution in the acetabulum using FEA with threedimensional (3D) computed tomography (CT).

\section{Methods}

The study utilized DICOM CT images (helical CT scanner, Lightspeed VCT; GE Medical Systems, Milwaukee, WI, USA; $1 \mathrm{~mm}$ slice thickness and $2.5 \mathrm{~mm}$ pitch) from 3 female patients. Based on the CT data, models were created for normal (35-year-old females; CE angle, $30^{\circ}$ ), borderline acetabular dysplasia (39-year-old female; CE angle, $20^{\circ}$ ), and an acetabular dysplasia hip (33-yearold female; CE angle, $0^{\circ}$ ) (Fig. 1). The rate of the femoral head cover and stress distribution of acetabulum were evaluated. In addition, the influence of the pelvic tilt on acetabular stress distribution was examined for pelvic anteversion, normal, and retroversion postures (Fig. 2). All patients provided informed consent and using of these data was conducted with the approval of our institutional ethical committee.

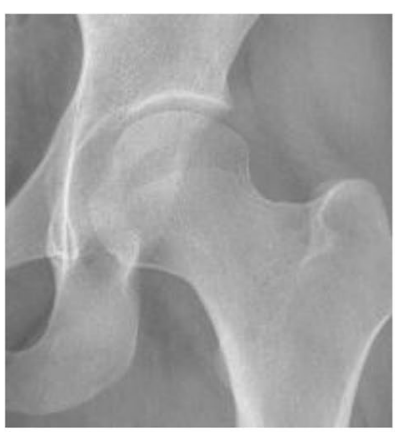

a

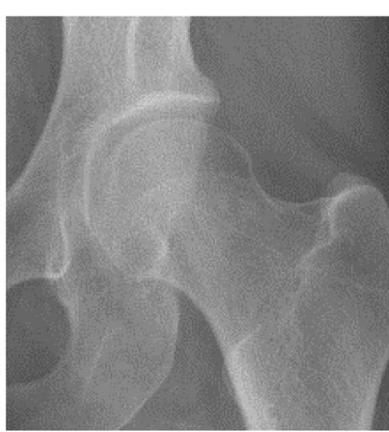

b

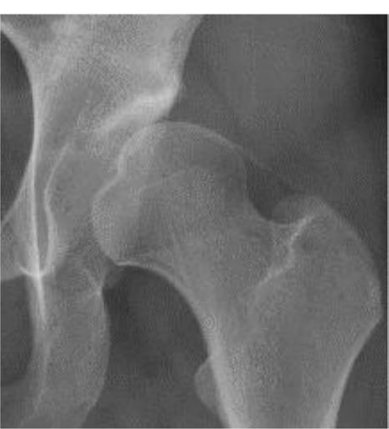

c

Fig. 1 Radiographs (anteroposterior view) of the 3 candidates in present study. a. 35 years female who was normal acetabulum (CE angle was $30^{\circ}$ ). b. 39 years female who was borderline acetabular dysplasia (CE angle was $20^{\circ}$ ). c. 33 years female who was acetabular dysplasia (CE angle was $0^{\circ}$ )

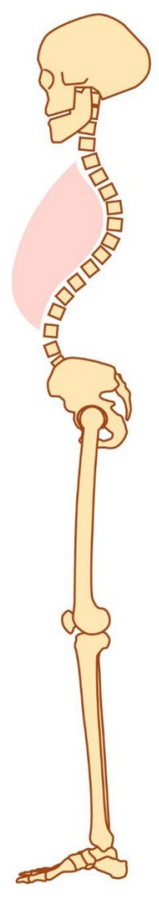

a

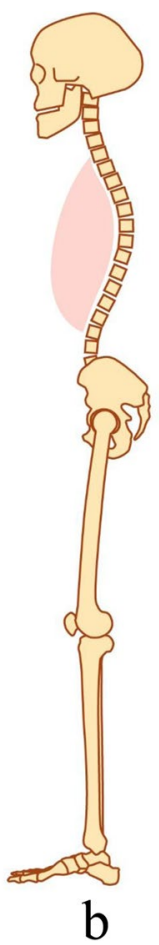

b

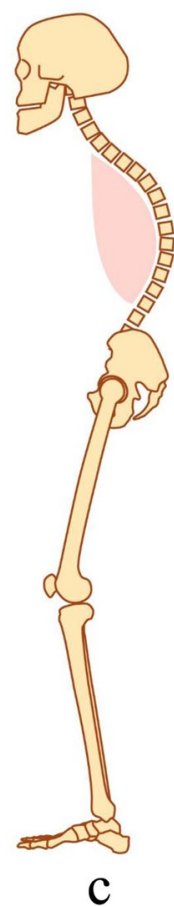

C

Fig. 2 The figures of pelvic postures. a. pelvic anteversion posture. b. pelvic normal posture. c. pelvic retroversion posture 


\section{Rate of femoral head cover}

CT-based templating software (ZedHip; Lexi Co, Tokyo, Japan) was used to measure the rate of femoral head cover [13]. The rate of femoral head cover was assessed at pelvic tilt angles (based on the anterior pelvic plane (APP)) of $20^{\circ}$ anteversion, $0^{\circ}$, and $20^{\circ}$ retroversion $\left(-20^{\circ}\right)$.

\section{Stress distribution of acetabulum: FEA}

Mechanical Finder Version 7.0 (RCCM Inc., Tokyo, Japan) was used to construct finite element modeling based on the 3D-CT data. Models for normal, borderline dysplasia, and a dysplasia hip (pelvis and femur) were created (Fig. 3). A cartilage layer with a mean thickness of approximately $1.5 \mathrm{~mm}$ on the femoral head and acetabulum was created using computer-aided design (CAD) data in all models. And the stress distribution on acetabular cartilage was evaluated (Fig. 4). Four noded linear solid tetrahedral elements were used for the pelvis, femur, and cartilage. Mesh size was $3 \mathrm{~mm}$. The mesh size and elements were set based on previous papers [6,7]. Briefly, the models were meshed using liner tetrahedral elements with a 3-mm element edge length, which were used in previous study conducted at our institute [6]. And Ike et al. evaluated that the pelvic FEA model created by Mechanical Finder (RCCM, Tokyo, Japan) with 2-4 mm mesh was the finest in sensitivity testing [7]. A total of 9 FEA models were created by adjusting the angle between the pelvis and the femur (normal, borderline dysplasia, and dysplasia models each at pelvic tilt

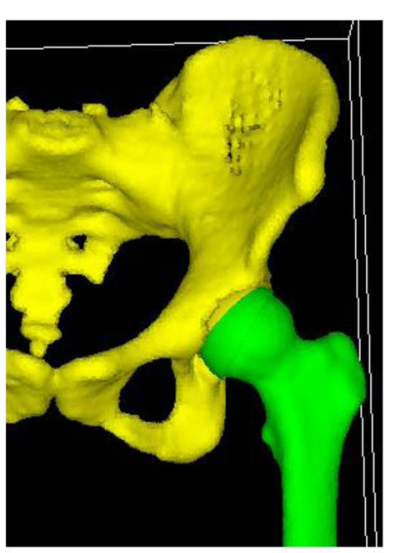

a

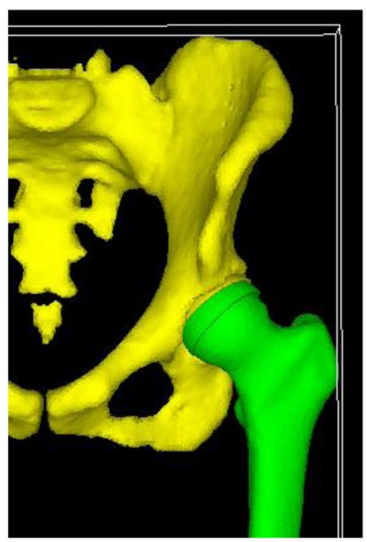

b

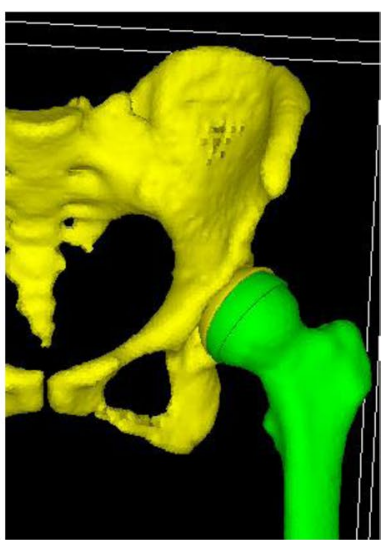

c

Fig. 3 The figures of FEA models. a. A model of normal acetabulum. b. A model of acetabular borderline dysplasia. c. A model of acetabular dysplasia

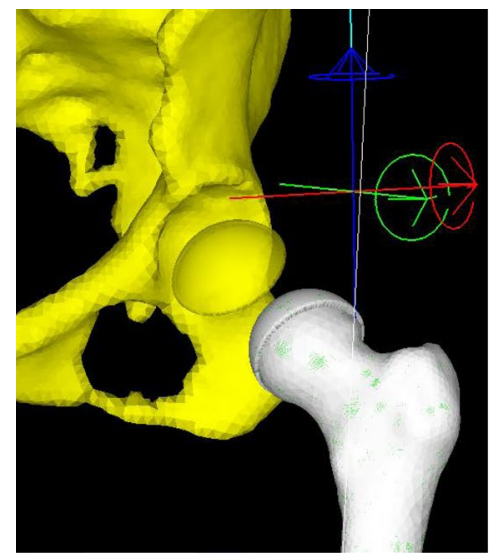

a

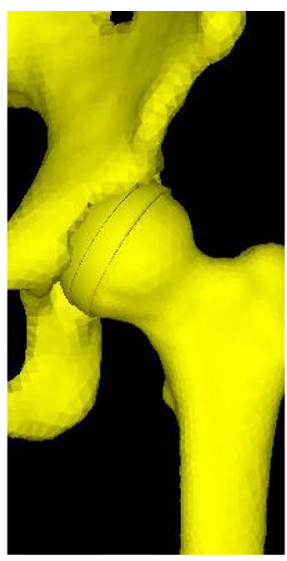

b

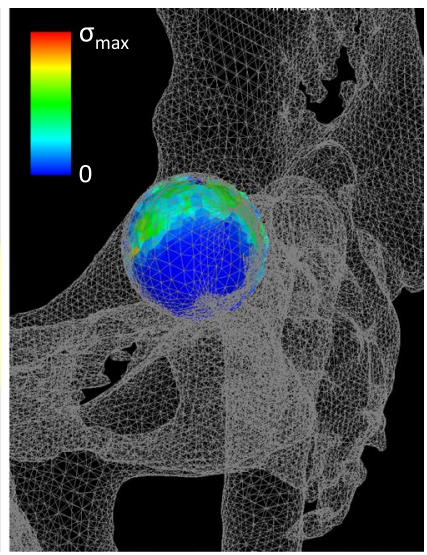

C

Fig. 4 a, b. The figures of FEA models. A cartilage layer with a mean thickness of approximately $1.5 \mathrm{~mm}$ on the femoral head and acetabulum was created using computer-aided design (CAD) data. c. the stress distribution on acetabular cartilage was evaluated in all models 
angles based on APP of $20^{\circ}, 0^{\circ}$, and $-20^{\circ}$ ) (Figs. 3 and 5). The solid was set in Mechanical Finder Version 7.0 (RCCM Inc., Tokyo, Japan). Non-uniform solid was used for the pelvis created from the CT data. Young's modulus was calculated from the Hounsfield units values of the CT data on the basis of Keyak's rule to determine the apparent density of each element (Tables 1 and 2) [14]. Uniform solid was used for cartilage and femur imported from CAD data.

Keyak's fomula states that the Poisson's ratio is constant at 0.25 . Poisson's ratio for the cartilage was set to 0.45 and femur was set to 0.3. Young's modulus for the cartilage was $15 \mathrm{MPa}$ and femur was $17,000 \mathrm{MPa}$. (Table 3) [14, 15]. The normal hip model consisted of 65,098 nodes and 291,469 elements, the borderline hip model consisted of 65,070 nodes and 295,145 elements, and the acetabular dysplasia hip model consisted of 63,070 nodes and 279,611 elements.

We created FEA models in the standing position with both legs, set the boundary conditions and loading conditions, and performed static analysis. For analysis, the body weight was placed on the superior aspect of the sacrum [15] with a vertical load of $400 \mathrm{~N}$, which was determined by subtracting the weight of the two legs from the body weight $(60 \mathrm{~kg})$. The load of the flexor muscles of the hip joint (iliopsoas and rectus femoris) was placed on the ilium and was calculated using the moment-arm equation (Fig. 5). In the boundary conditions, the distal end of the bilateral femur was fixed in all directions. And, the stress distribution on acetabular cartilage was evaluated using the maximum von Mises stress.

\section{Results}

\section{Rate of femoral head cover}

With a pelvic tilt angle of $20^{\circ}$, the rate of femoral head cover in the normal, borderline dysplasia, and dysplasia
Table 1 The conversion equation from Hounsfield units to bone density $(p ; g / c m 3)$

$\mathrm{p}=(\mathrm{HU}+1.4246) \times 0.001 / 1.0580:(-1<\mathrm{HU})$

$\mathrm{p}=1.0 \times 10^{-8}:(\mathrm{HU} \leq-1)$

$\mathrm{HU}$ : Hounsfield units

Table 2 Keyak's fomula

\begin{tabular}{ll}
\hline Bone density $\left(\mathbf{p} ; \mathbf{g} / \mathbf{c m}^{\mathbf{3}}\right)$ & $\begin{array}{l}\text { Young's } \\
\text { modulus }(\mathrm{E} ; \\
\mathbf{M P a})\end{array}$ \\
\hline $\mathrm{p}=0$ & 0.001 \\
$0<\mathrm{p} \leq 0.27$ & $33900 \mathrm{p}^{2.20}$ \\
$0.27<\mathrm{p} \leq 0.60$ & $5307 \mathrm{p}+469$ \\
$0.60 \leq \mathrm{p}$ & $10200 \mathrm{p}^{2.01}$ \\
\hline
\end{tabular}

models was $50.3 \%, 44.5 \%$, and $43.4 \%$, respectively. With a pelvic tilt angle of $0^{\circ}$, the rate was $47.5 \%, 39.7 \%$, and $35.7 \%$, respectively. With a pelvic tilt angle of $-20^{\circ}$, the rate was $38.9 \%, 31.4 \%$, and $30.2 \%$, respectively (Fig. 6). Thus, all three models showed the highest rate of femoral head cover with a $20^{\circ}$ pelvic tilt angle, and the lowest rate with a $-20^{\circ}$ angle. Moreover, the borderline dysplasia model with a $-20^{\circ}$ pelvic tilt angle demonstrated a lower rate of femoral head cover compared to that for the dysplasia model with a pelvic tilt angle of $0^{\circ}$.

\section{Stress distribution on the acetabulum: FEA}

In the normal model, the stress distribution was widely concentrated around the load-bearing area. When

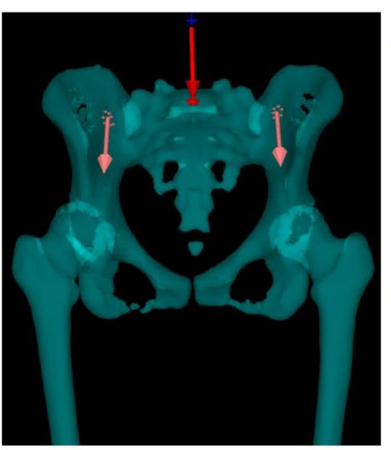

a

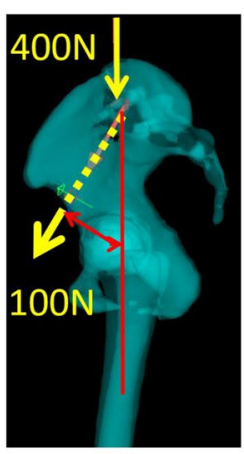

b

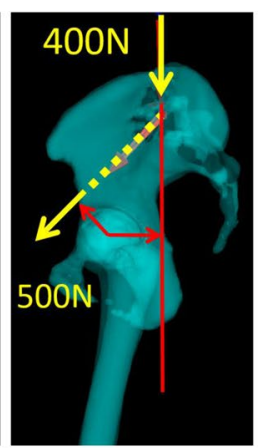

C

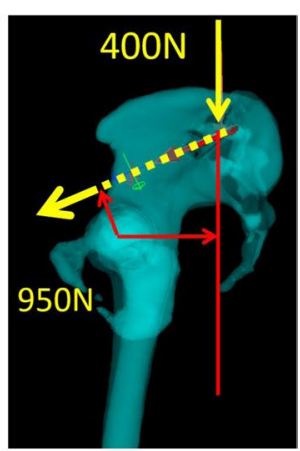

d

Fig. 5 The FEA model that showed body weight was placed on the superior aspect of the sacrum and the load of the flexor muscles of the hip joint was placed on the ilium. a. Anteroposterior view of the FEA model. b. Lateral view of pelvic $20^{\circ}$ anteversion model. The load of the flexor muscle $(100 \mathrm{~N})$ of the hip was calculated using the moment arm equation. c. Lateral view of pelvic 0 anteversion model. The load of the flexor muscle $(500 \mathrm{~N})$ of the hip was calculated using the moment arm equation. $\mathbf{d}$. Lateral view of pelvic $20^{\circ}$ retroversion model. The load of the flexor muscle $(950 \mathrm{~N})$ of the hip was calculated using the moment arm equation 
Table 3 material properties

\begin{tabular}{lll}
\hline Material & Young's Modulus (E; MPa) & Poisson's ratio \\
\hline Pelvic bone & Keyak's formula & 0.25 \\
Femoral bone & 17,000 & 0.3 \\
Cartilage & 15 & 0.45 \\
\hline
\end{tabular}

the pelvis was tilted backwards, the stress distribution showed a tendency to focus on the load-bearing area. In the borderline dysplasia model, the stress distribution was concentrated in the anterior and posterior load-bearing area. In addition, the stress distribution was strongly concentrated in the anterior load-bearing area at a pelvic tilt angle of $-20^{\circ}$. Similarly, in the dysplasia model, the stress distribution was concentrated in the anterior and posterior load-bearing area, and when the pelvis was tilted backwards, the stress distribution showed a tendency to focus on the anterior load-bearing area. All three models showed the highest von Mises stress value with a $-20^{\circ}$ pelvic tilt angle, and the lowest stress values with a $20^{\circ}$ angle. The borderline dysplasia model with a pelvic tilt angle of $-20^{\circ}$ had a similar maximum von Mises stress value compared to that for the dysplasia model of pelvic tilt angle of $0^{\circ}$ (3.5 Mpa and 3.1 Mpa, respectively) (Figs. 7 and 8).

\section{Discussion}

Recently, pelvic retroversion was reported to result in decreased acetabular cover of the femoral head [16]. In patients with osteoarthritis of the hip, pelvic anteversion is thought to increase the rate of femoral head cover and decrease the load on the acetabulum. Moreover, pelvic retroversion with lumber degenerative kyphosis results in decreased acetabular cover of the femoral head and increased load on the acetabulum [5]. In the present study, models for normal, borderline dysplasia, and dysplasia hips showed the highest von Mises stress in pelvic retroversion, and the lowest in pelvic anteversion. These results demonstrate that pelvic retroversion increases the stress on the acetabulum regardless of pelvic shape.

In the present study, the body weight was placed on the superior aspect of the sacrum based on previous research [15]. By necessity, the load on the flexor muscles of the hip joint was calculated using the momentarm equation against this body weight to keep the attitude. The body weight for all models was unified to $400 \mathrm{~N}$ in order to unify the load conditions across models. Young's modulus was calculated from the Hounsfield values in the CT data on the basis of Keyak's rule to determine the apparent density of each element in pelvis as in previous studies [14]. Furthermore, the transmission of the cartilage layer separating the two layers of the acetabular and femoral head sides was designed to closely model the living body.

In the normal hip model, the stress distribution was widely concentrated around the load-bearing area, showing a tendency to focus on the load-bearing area when the pelvis was tilted backwards. In contrast, the stress distribution was concentrated in the anterior and posterior load-bearing area in the borderline dysplasia model, and the stress distribution was strongly concentrated in the anterior load-bearing area at a pelvic tilt angle of $-20^{\circ}$. Thus, three-dimensional acetabular dysplasia was involved in addition to the low CE angle for the borderline pelvis [17-19].

Dysplasia results in osteoarthritis of the hip due to decreased acetabular cover of the femoral head $[1,2$, $20,21]$. Until now, few reports exist on the use of FEA

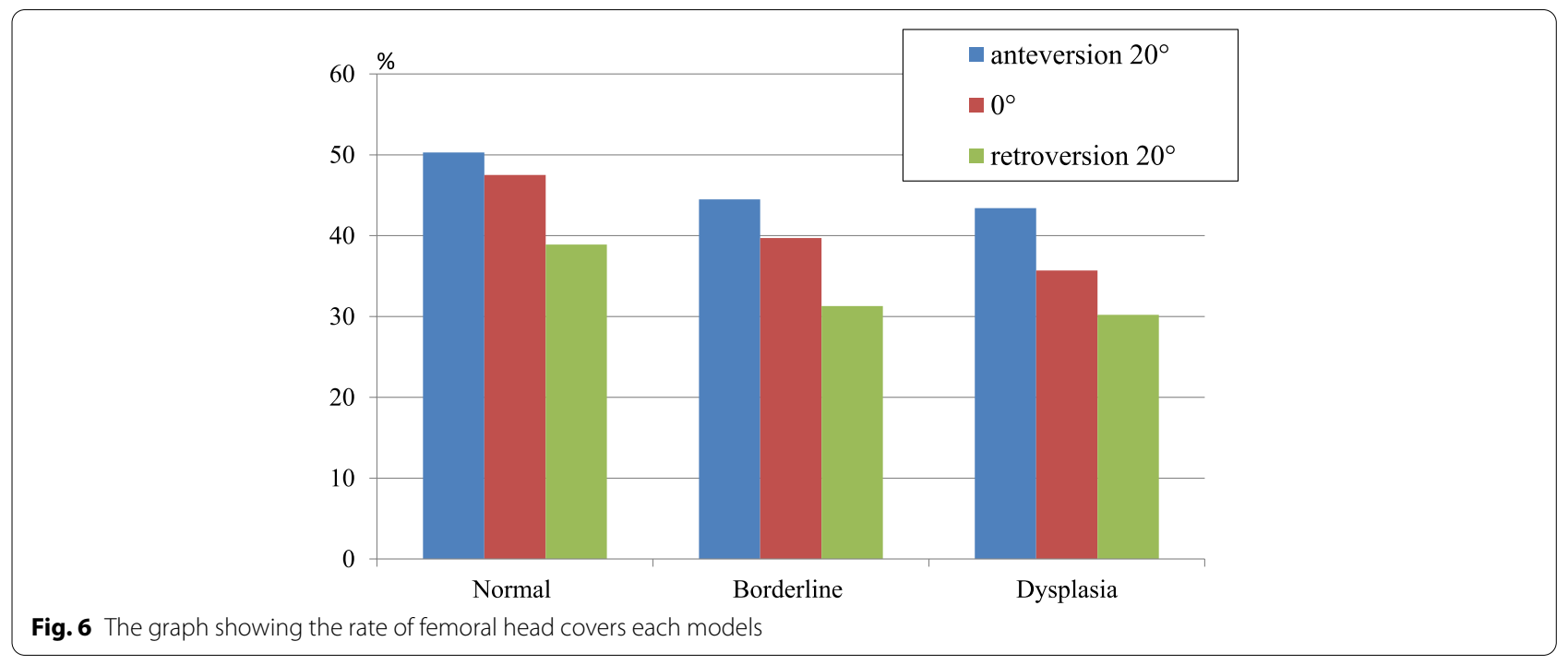




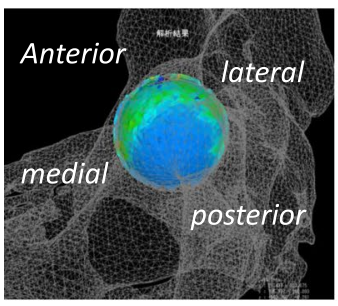

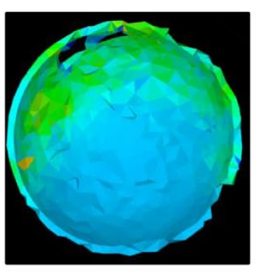

a

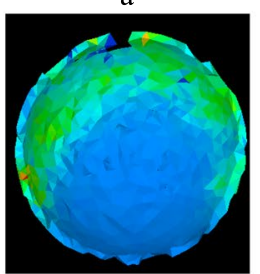

b

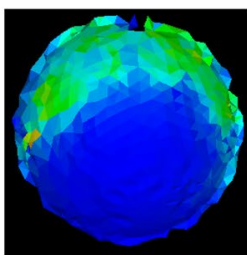

c

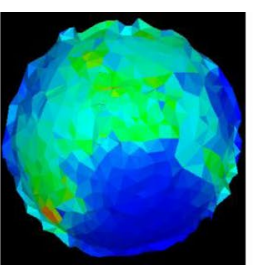

d

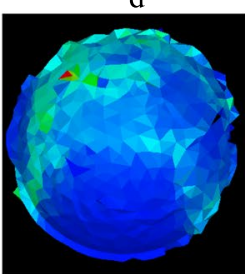

e

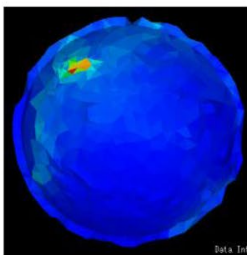

f

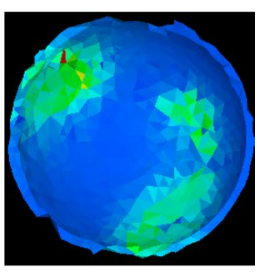

g

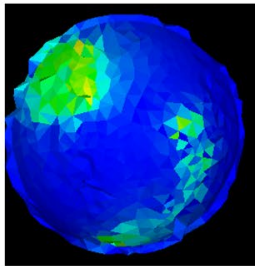

$\mathrm{h}$

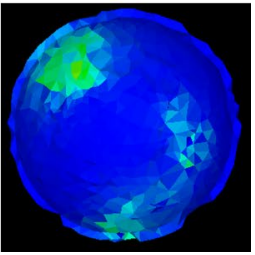

i

Fig. 7 The figure showing stress distribution on acetabular cartilage. a. The normal hip at pelvic tilt angles of $20^{\circ}$. $\mathbf{b}$. The normal hip at pelvic tilt angles of $0^{\circ}$. c. The normal hip at pelvic tilt angles of $-20^{\circ}$. d . The acetabular borderline dysplasia at pelvic tilt angles of $20^{\circ}$. e. The acetabular borderline dysplasia at pelvic tilt angles of $0^{\circ}$. f. The acetabular borderline dysplasia at pelvic tilt angles of $-20^{\circ}$. $\mathbf{g}$. The acetabular dysplasia at pelvic tilt angles of $20^{\circ}$. $\mathbf{h}$. The acetabular dysplasia at pelvic tilt angles of $0^{\circ}$. i. The acetabular dysplasia at pelvic tilt angles of $-20^{\circ}$

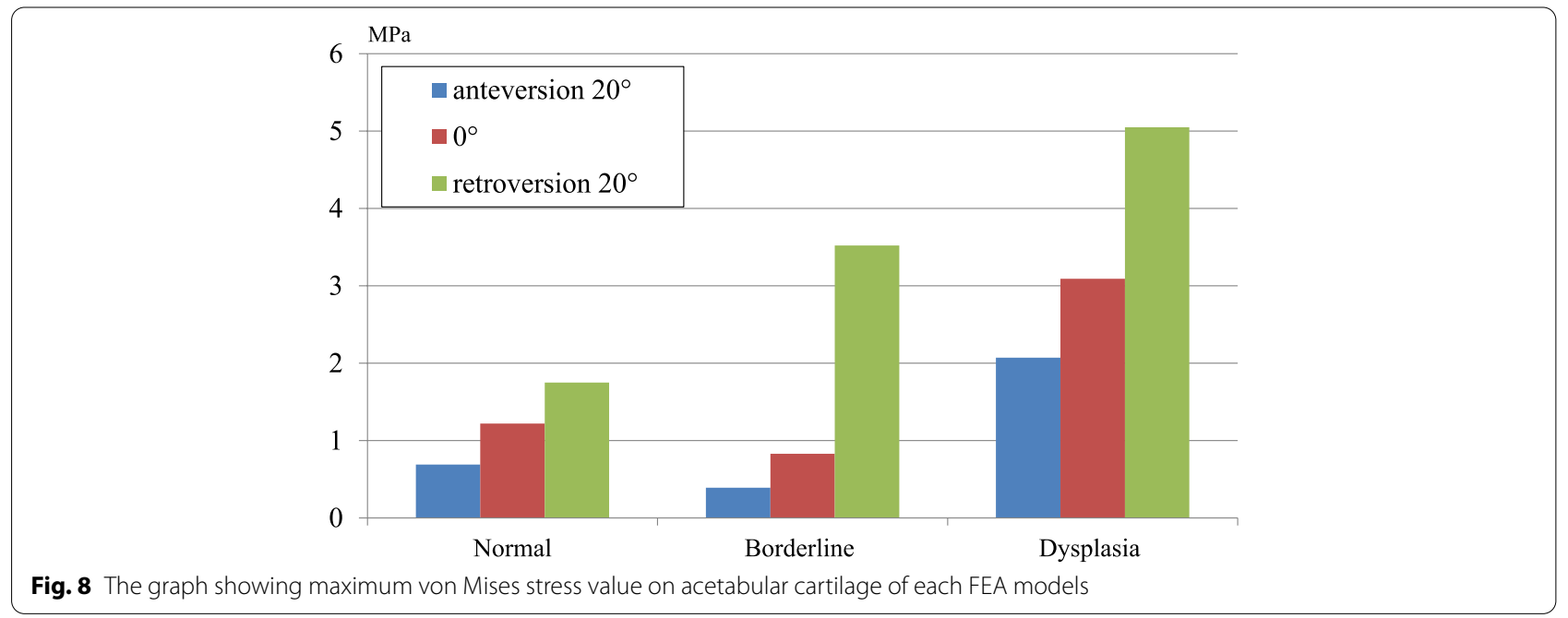

in evaluating the effects of pelvic tilt on stress distribution in the acetabulum. In the present study, we were able to assess of the influence of pelvic tilt on stress distribution in the acetabulum. The load in the borderline dysplasia model at a pelvic tilt angle of $-20^{\circ}$ was similar to that for the dysplasia model at a pelvic tilt angle of $0^{\circ}$, which is a risk factor for osteoarthritis. Therefore, borderline dysplasia with a pelvic tilt angle of $-20^{\circ}$ may also be a risk factor for osteoarthritis of the hip.

The present study has several limitations to discuss. First, the number of the patients was limited due to the involvement of FEA. Second, dysplasia, borderline dysplasia, and a normal pelvis could not be compared in similar patients. Thus, models of different patients were compared. Third, the study did not examine data of a dynamic condition. 


\section{Conclusions}

In conclusion, pelvic retroversion resulted in decreased acetabular cover of the femoral head and increased load on the hip joint. A pelvic tilt angle of $-20^{\circ}$ in borderline dysplasia had a similar maximum von Mises stress value as that for a pelvic tilt angle of $0^{\circ}$ in dysplasia, suggesting that a pelvic retroversion of $-20^{\circ}$ in borderline dysplasia is a risk factor for osteoarthritis of the hip joints.

\section{Abbreviations}

FEA: Finite element analysis; THA: Total hip arthroplasty; CE: Central-edge; APP: Anterior pelvic plane; CAD: Computer-aided design.

\section{Acknowledgements}

Not applicable.

\section{Authors' contributions}

TK conceived the study. JS and KH constructed finite element modeling. $\mathrm{KH}$ analyzed the data, and wrote the first draft of the manuscript. HT and TK provided the critical comments to design the study. YK and DI provided additional advice. All authors read and approved the final manuscript.

\section{Funding}

No funds were received in support of this work.

\section{Availability of data and materials}

The datasets used and/or analysed during the current study are available from the corresponding author on reasonable request.

\section{Declarations}

Ethics approval and consent to participate

The study protocol was approved by the Ethics Committee of the Kanazawa university. All procedures were performed in accordance with relevant guidelines. All patients provided informed consent prior to their inclusion in this study.

\section{Consent for publication}

Not applicable.

\section{Competing interests}

The authors declare that they have no competing interests.

\section{Author details}

1 Department of Orthopaedic Surgery, Suzu General Hospital, 1-1 Nonoemati, Ishikawa 927-1213 Suzu, Japan. ${ }^{2}$ Department of Orthopaedic Surgery, Graduate School of Medical Science, Kanazawa University, 13-1 Takaramachi, Ishikawa 920-8641 Kanazawa, Japan. ${ }^{3}$ Bio Engineering Laboratory, School of Mechanical Engineering, Kanazawa University, Kakumamati, Ishikawa 920-1192 Kanazawa, Japan.

Received: 15 November 2020 Accepted: 14 June 2021

Published online: 06 September 2021

\section{References}

1. Jingushi S, Ohfuji S, Sofue M, Hirota Y, Itoman M, Matsumoto T, et al. Multiinstitutional epidemiological study regarding osteoarthritis of the hip in Japan. J Orthop Sci. 2010;15:626-31.

2. Jingushi S, Ohfuji S, Sofue M, Hirota Y, Itoman M, Matsumoto T, et al. Osteoarthritis hip joints in Japan: involvement of acetabular dysplasia. J Orthop Sci. 2011;16:156-64.
3. Wiberg G. Studies on dysplastic acetabula and congenital subluxation of the hip joint: with special reference to the complication of osteoarthritis. Acta Chir Scand. 1939;83(Suppl 58):1-135.

4. Wiberg G. Shelf operation in congenital dysplasia of the acetabulum and in subluxation and dislocation of the hip. J Bone Joint Surg Am. 1953;35:65-80.

5. Yoshimoto H, Sato S, Masuda T, Kanno T, Shundo M, Hyakumachi T, et al. Spinopelvic alignment in patients with osteoarthrosis of the hip: a radiographic comparison to patients with low back pain. Spine. 2005;30:1650-7.

6. Sakagoshi D, Kabata T, Umemoto Y, Sakamoto J, Tomita K. A mechanical analysis of femoral resurfacing implantation for osteonecrosis of the femoral head. J Arthroplasty. 2010;25:1282-9.

7. Ike H, Inaba Y, Kobayashi N, Yukizawa Y, Hirata Y, Tomioka M, et al. Effects of rotational acetabular osteotomy on the mechanical stress within the hip joint in patients with developmental dysplasia of the hip: a subjectspecific finite element analysis. Bone Joint J. 2015;97:492-7.

8. Okamoto Y, Murakami H, Demura S, Kato S, Yoshioka K, Hayashi H. The effect of kyphotic deformity because of vertebral fracture: a finite element analysis of $10^{\circ}$ and $20^{\circ}$ wedge-shaped vertebral fracture model. Spine J. 2015;15:713-20.

9. Zhang X, Yuan S, Wang J, Liao B, Liang D. Biomechanical characteristics of tibio-femoral joint after partial medial meniscectomy in different flexion angles: a finite element analysis. BMC Musculoskelet Disord. 2021;22:322.

10. Ren D, Liu Y, Zhang X, Song Z, Lu J, Wang P. The evaluation of the role of medial collateral ligament maintaining knee stability by a finite element analysis. J Orthop Surg Res. 2017;12:64.

11. Liu X, Ma J, Park P, Huang X, Xie N, Ye X. Biomechanical comparison of multilevel lateral interbody fusion with and without supplementary instrumentation: a three dimensional finite element study. BMC Musculoskelet Disord. 2017;18:63.

12. Liu C, llieu Kamara A, Yan Y. Investigation into the biomechanics of lumbar spine micro-dynamic pedicle screw. BMC Musculoskelet Disord. 2018;19:200.

13. Ueno T, Kabata T, Kajino Y, Ohmori T, Yoshitani J, Tsuchiya H. Three-Dimensional Host Bone Coverage Required in Total Hip Arthroplasty for Developmental Dysplasia of the Hip and Its Relationship With 2-Dimensional Coverage. J Arthroplasty. 2019;34:93-101.

14. Keyak JH, Rossi SA, Jones KA, Skinner HB. Prediction of femoral fracture load using automated finite element modeling. J Biomech. 1998;31:125-33.

15. Zhao X, Chosa E, Totoribe K, Deng G. Effect of periacetabular osteotomy for acetabular dysplasia clarified by three-dimensional finite element analysis. J Orthop Sci. 2010;15:632-40.

16. Dandachli W, UI Islam S, Richards R, Hall-Craggs M, Witt J. The influence of pelvic tilt on acetabular orientation and cover: a three-dimensional computerised tomography analysis. Hip Int. 2013;23:87-92.

17. Chosa E, Tajima N. Anterior acetabular head index of the hip on falseprofile views. New index of anterior acetabular cover. J Bone Joint Surg Br. 2003;85:826-9.

18. Zingg PO, Werner CM, Sukthankar A, Zanetti M, Seifert B, Dora C. The anterior center edge angle in Lequesne's false profile view: interrater correlation, dependence on pelvic tilt and correlation to anterior acetabular coverage in the sagittal plane. A cadaver study. Arch Orthop Trauma Surg. 2009;129:787-91.

19. Fujii M, Nakashima Y, Sato T, Akiyama M, Akiyama M, Iwamoto Y. Acetabular tilt correlates with acetabular version and coverage in hip dysplasia. Clin Orthop Relat Res. 2012;470:2827-35.

20. Reijman M, Hazes JM, Pols HA, Koes BW, Bierma-Zeinstra SM. Acetabular dysplasia predicts incident osteoarthritis of the hip: the Rotterdam study. Arthritis Rheum. 2005;52:787-93.

21. Jacobsen S, Sonne-Holm S, Soballe K, Gebuhr P, Lund B. Hip dysplasia and osteoarthrosis: a survey of 4151 subjects from the Osteoarthrosis Substudy of the Copenhagen City Heart Study. Acta Orthop. 2005;76:149-58.

\section{Publisher's Note}

Springer Nature remains neutral with regard to jurisdictional claims in published maps and institutional affiliations. 